\title{
A RARE CASE OF GIANT ADRENOCORTICAL CARCINOMA
}

Abinash Hazarika, T. M. Manohar, M.S. Sushruta, Uchil Sonali Raghav

1. Associate Professor. Department of General Surgery, Adichunchanagiri Institute of Medical Sciences, B.G.
Nagara, Nagamangala Taluk, Mandya district, Karnataka.
2. Professor \& HOD. Department of General Surgery, Adichunchanagiri Institute of Medical Sciences, B.G.
Nagara, Nagamangala Taluk, Mandya district, Karnataka.
3. Associate Professor. Department of General Surgery, Adichunchanagiri Institute of Medical Sciences, B.G.
Nagara, Nagamangala Taluk, Mandya district, Karnataka.
4. Post Graduate. Department of General Surgery, Adichunchanagiri Institute of Medical Sciences, B.G.
Nagara, Nagamangala Taluk, Mandya district, Karnataka.

\section{CORRESPONDING AUTHOR:}

Dr. Abinash Hazarika,

Professor Quarters, No 22, B Block, AIMS,

B.G. Nagara, Nagamangala Taluk, Mandya district,

Karnataka- 571448.

E-mail: hazarikadrabinash@gmail.com

ABSTRACT: Adrenocortical carcinomas are rare incidentalomas usually found on abdominal imaging studies. Functional carcinomas usually present early whereas non functioning adrenocortical carcinomas have a delayed presentation due absence of symptoms. Here is a similar case of a 45 year old lady who presented with large retroperitoneal mass which reported to be adrenocortical carcinoma on histopathology due non functioning nature of the tumour. Such tumors are diagnosed with a delay as they seldom produce any symptoms and rarely attain a large size as in this case.

KEY WORDS: Retroperitoneal tumour, Adrenocortical tumour, Adrenocortical carcinoma

INTRODUCTION: Adrenocortical carcinoma is a rare tumour having an incidence of 1-2 /million/year with a female to male ratio of 1.5:1. It can occur at any age, with bimodal peaks in the first decade and the fourth decade. Most cases are sporadic whereas some are syndromic.

$60 \%$ of the tumours are functional with adults presenting with cushing's syndrome, combined with virilization or virilization alone.<10\% present with estrogen or mineralocorticoid excess. Children present more commonly with virilization.

The rest of the tumours are non secreting tumours. Presenting with abdominal pain, fever\& leukocytosis or could be asymptomatic diagnosed with incidental adrenal mass. ${ }^{1}$

Definitive diagnosis obtained by CT and MRI.

Patients with adrenocortical carcinoma are treated using multidisciplinary approach using combined surgery, radiotherapy and chemotherapy. ${ }^{2}$

CASE SUMMARY: 45 Year old housewife from a rural area presented with upper abdominal pain since 2 years which aggravated since 3 months. Pain felt in the left upper abdomen radiating to back, dull aching, intermittent and relieved by analgesics. She was treated by a local doctor for pain abdomen and said to have mass per abdomen 2 months back. She complains of impaired appetite and weakness. There is history of malaria 2 years back for which she was treated and recovered completely. There is no significant weight loss, bowel or bladder disturbances. Not a known diabetic or hypertensive 
ON EXAMINATION- Patient is moderately built and nourished with Pulse of 82 beats per minute, Blood Pressure of $130 / 80 \mathrm{~mm}$ of $\mathrm{Hg}$.

ON INSPECTION - Fullness was noted in the left hypochondriac region extending into epigastric, umbilical and left lumbar region. ON PALPATION- A palpable mass of 10x8cm,with no local rise of temperature, tender on palpation, firm, does not move with respiration, non mobile, smooth surfaced, cannot insinuate fingers between the mass and the costal margin and does not fall forward on knee elbow position. No other organomegaly.

ON PERCUSSION - Dull note found over the swelling. No free fluid in the abdomen. ON AUSCULTATION- Bowel sounds were normal. No bruit heard over the swelling. Per vaginal and per rectal examination- normal

No supraclavicular or other peripheral lymph nodes palpable

INVESTIGATIONS -Blood routine - $(\mathrm{Hb}=12.7 \mathrm{gm} \% ; \mathrm{TC}=9800$ cells/Cumm; $\mathrm{N}=76$, $\mathrm{L}=21, \mathrm{~B}=2, \mathrm{M}=1$;) ESR $-25 \mathrm{~mm} /$ hour. Urine routine -normal. Coagulation profile - $\mathrm{BT}=4^{\prime} 10^{\prime \prime}$; CT=6'18". PT-11.23 secs, APTT-25.8secs. Platelet count - 2.3lakhs/cu mm. Blood urea- 25mg/dl. RBS $-131 \mathrm{mg} / \mathrm{dL}$. Serum creatinine $-0.8 \mathrm{mg} / \mathrm{dL}$. Peripheral blood smear - Normocytic normochromic blood picture. LFT within normal limits. Chest X-ray, OGD, ECG and 2D ECHO were normal.

IMAGING STUDIES: Plain CT and contrast enhanced CT scan of the abdomen was done.

\section{Differential Diagnosis on Imaging}

1. Primary retroperitoneal malignancy

[Likely differentials:

a. malignant fibrous histiocytoma / dedifferentiated-pleomorphic liposarcoma.

b. leiomyosarcoma]

2. Adrenocortical carcinoma

SURGERY AND FINDINGS: Under GA, elective laparotomy done and proceeded with a midline incision extending $2 \mathrm{~cm}$ below xiphisternum to $8 \mathrm{~cm}$ below umbilicus. A large well encapsulated mass measuring $11 \times 20 \mathrm{~cm}$ noted in the left hypochondrium, left lumbar region, and epigastric region. Spleen pushed laterally and superiorly, tail of pancreas and transverse colon pushed medially by the mass. Left kidney pushed inferiorly. High vascularity noted, dilated vessels present over the mass. Inferiormesentric vein and splenic vessels pushed away by the mass secured. Feeding vessels ligated. Enucleation of the mass done. Drains placed in the right and left pelvic regions.

POST OPERATIVELY: Patient was shifted to Intensive care unit. Monitoring of vitals were stable. Blood pressure was maintained throughout. Started orally on the third day. Shifted out of ICU on 4th post-op day.

HISTOPATHOLOGY - MICROSCOPY: Points in favor of adrenocortical carcinoma from adenoma

Modified Weiss system (Aubert and Collegues) ${ }^{1}$ 
- Mitotic rate $>5 / \mathrm{HPF}-2$

- Cytoplasm ( $<25 \%$ Clear cells)- 2

- Abnormal mitoses- 1

- Necrosis - 1

- Capsular invasion- 1

\section{Score of $\geq 3$ Carcinoma}

In our case:

Cytoplasm (<25\% clear cells)[2]+ Abnormal mitoses[1]+ Necrosis[1] = 4

Malignant Adrenal cortical tumor, i.e., adrenocortical carcinoma

DISCUSSION A non secreting adrenocortical carcinoma can mimic a retroperitoneal tumour in number of ways and thus, should always be considered in the differential diagnosis. Complete resection by an expert surgeon is the only potentially curative treatment for Adrenocortical carcinoma.

Prognosis of the patient depends on Age of the patient and Stage of the tumor. Poor prognostic factors being Weight of $50 \mathrm{~g}+$; Diameter of $6.5 \mathrm{~cm}+$, Mitotic activity, venous invasion, Ki-67/MIB1 labeling index of 4\%+, p53+.

Probable preoperative diagnosis is essential suspicious adrenal lesions for proper management. Needs special multidisciplinary approach to manage such cases

\section{REFERENCES:}

1. Lacroix A. Approach to the patient with adrenocortical carcinoma. J ClinEndocrinolMetab. 2010 Nov; 95(11):4812-22.

2. Ni H, Htet A. Adrenal cortical carcinoma masquerading as pheochromocytoma: a case report. Ecancermedicalscience. 2012;6:277.

3. Symeonidis D, Chatzinikolaou I, Koukoulis G, Mamaloudis I, Tepetes K. Adrenocortical carcinoma presenting with signs of acute abdomen.Case Rep Surg. 2013;2013:132726

4. Sidalingareddy, Andola S K. Fine Needle Aspiration Cytology of Intra-Abdominal Lesions. JCDR. 2011; 5(3): 551-558.

5. Stewart CJ, Coldewey J, Stewart IS. Comparison of fine needle aspiration cytology and needle core biopsy in the diagnosis of radiologicallydetectedabdominal lesions. J ClinPathol. 2002 Feb;55(2):93-7.

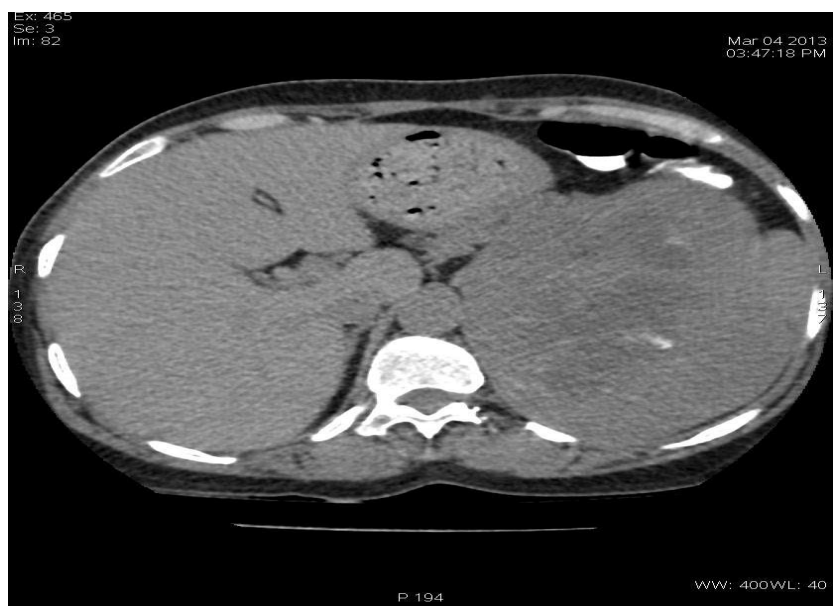


Large well defined retroperitoneal mass seen in the left supra renal region. The mass is heterogenous on NECT and shows heterogenous enhancement on CECT images.Thehypodense, non enhancing areas within the mass are likely to represent necrosis. The hyperdense foci within the mass are likely to represent hemorrhages and calcifications.

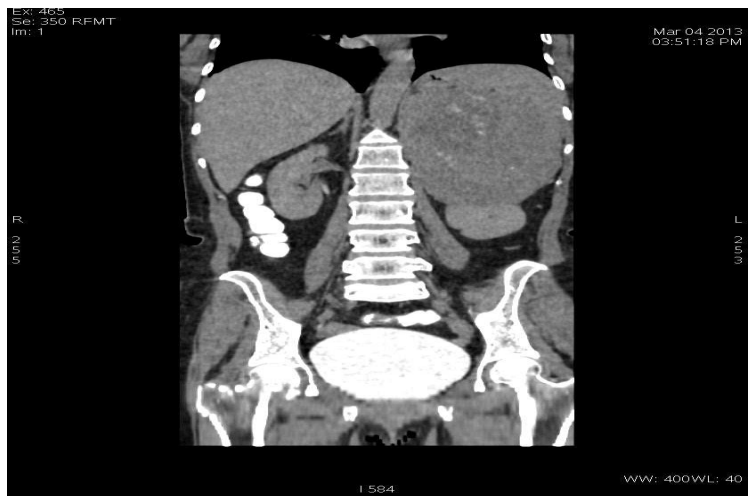

The mass is seen to displace the left kidney inferiorly. The fat plane between lesion and pancreatic body \& tail, lesion \& spleen and lesion \& superior pole of kidney fails to identified at certain places.

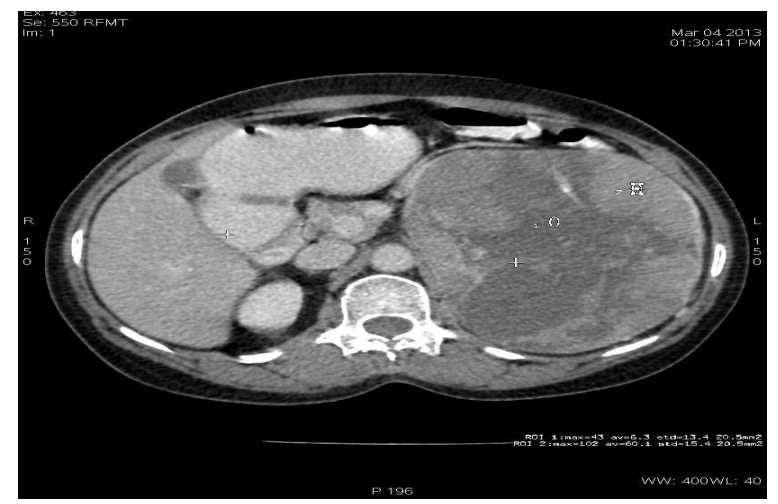

Left adrenal is not separately visualised from the lesion. The fat plane between the splenic vessels and the lesion fails to be identified.

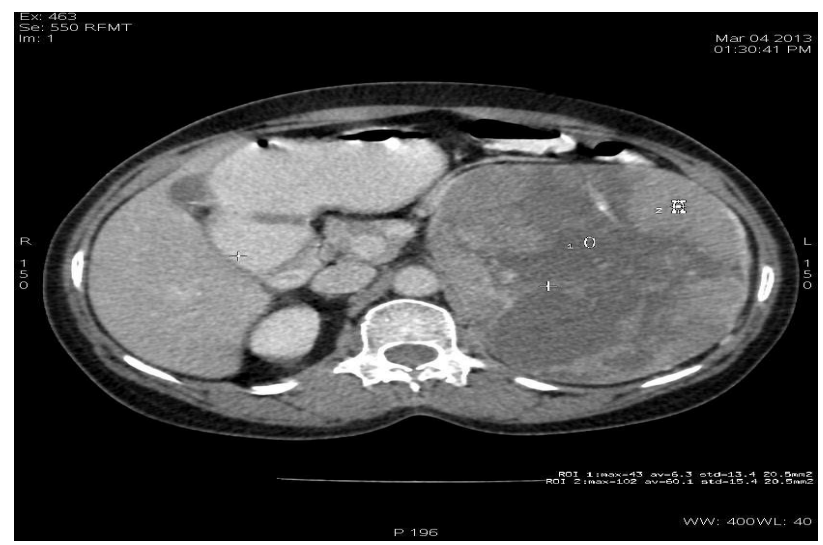


The lesion is seen to abut stomach, and the bowel loops anteriorly, left hemidiaphragm superiorly; left crus of diaphragm medially; however the fat plane between the lesion and these structures is maintained.

Aorta, Celiac trunk, SMA, Left Renal vessels appear to be uninvolved.

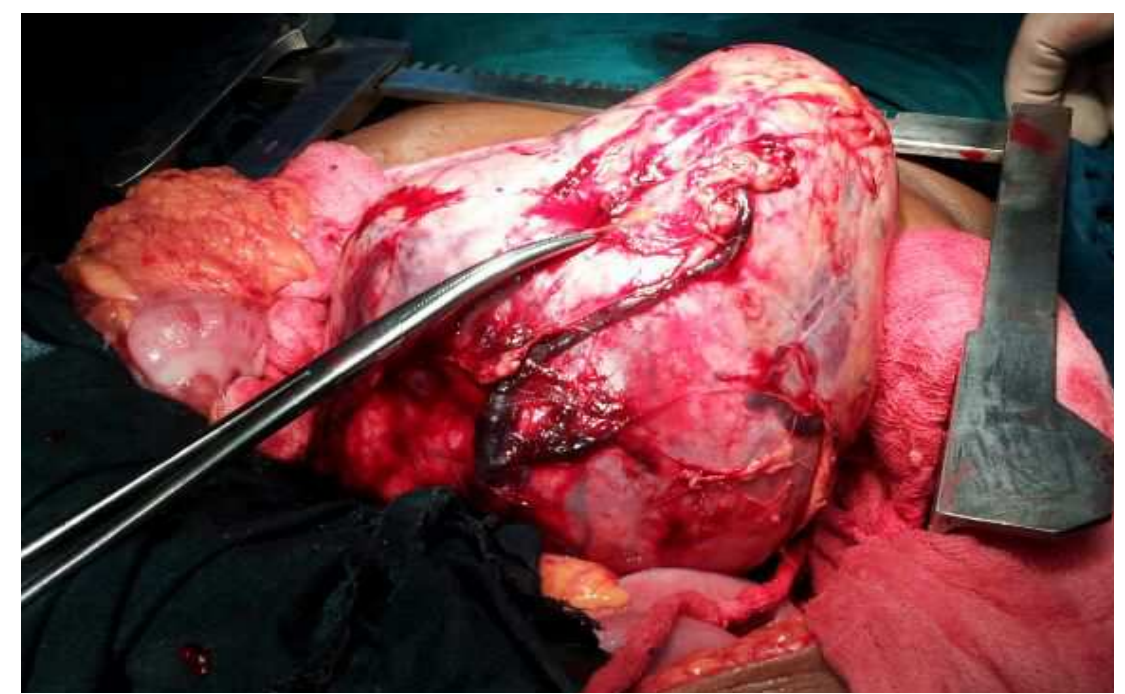

On table picture of the retroperitoneal mass

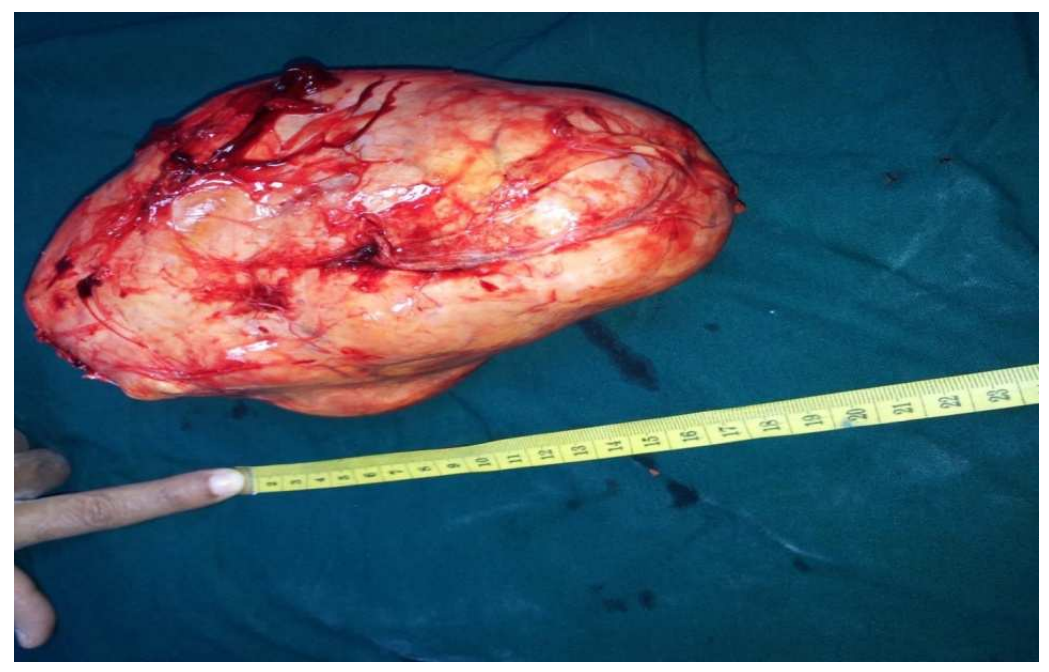

Specimen after enucleation. Large vessels seen over the surface. Measures $21 \times 15 \times 14 \mathrm{~cm}$ and weighs 650gms.

External surface: Capsulated Globular, sold, firm mass. Grey yellow in color. 


\section{CASE REPORT}

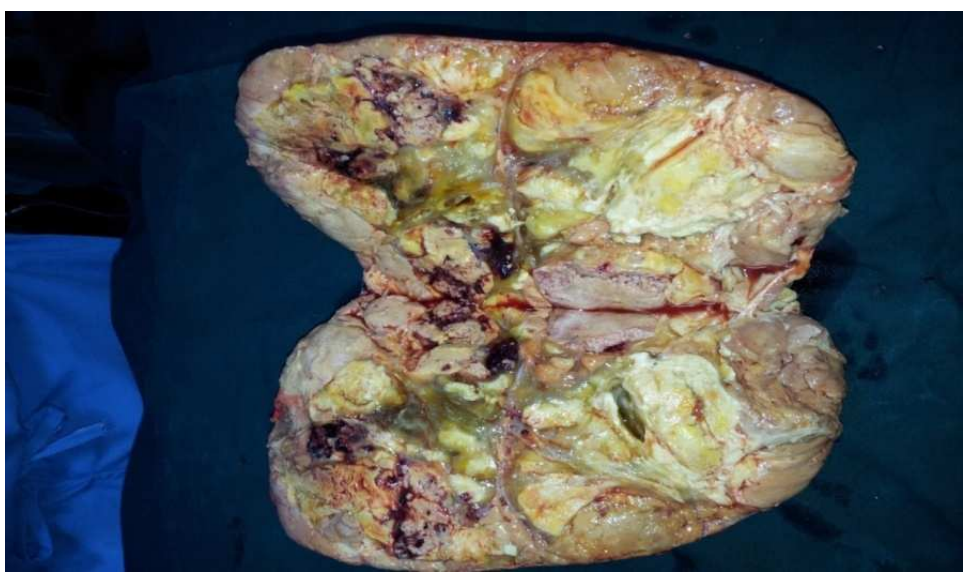

Grey yellow to tan yellow in color, Shows nodular areas, Focal areas of hemorrhage, Myxoid region and Areas of necrosis seen on cut section

Histopathology microscopy

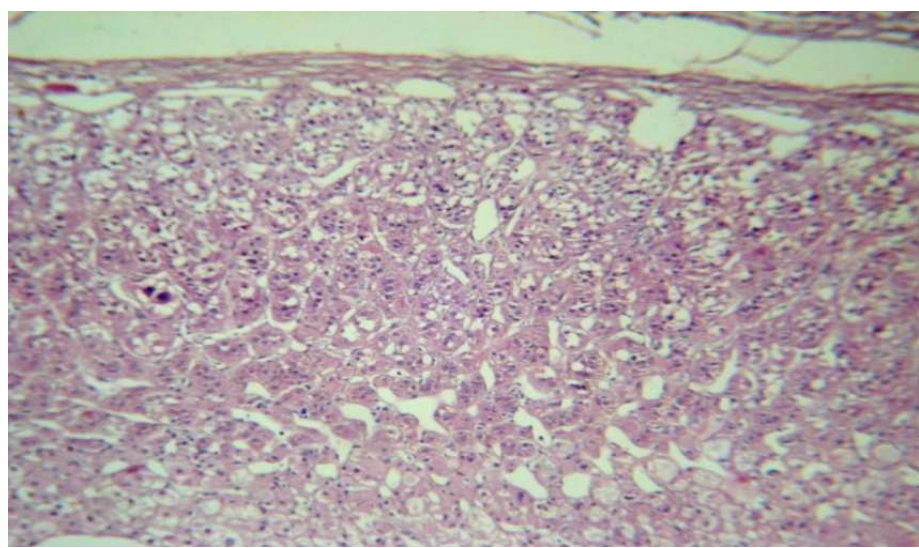

Slide showing normal adrenal tissue

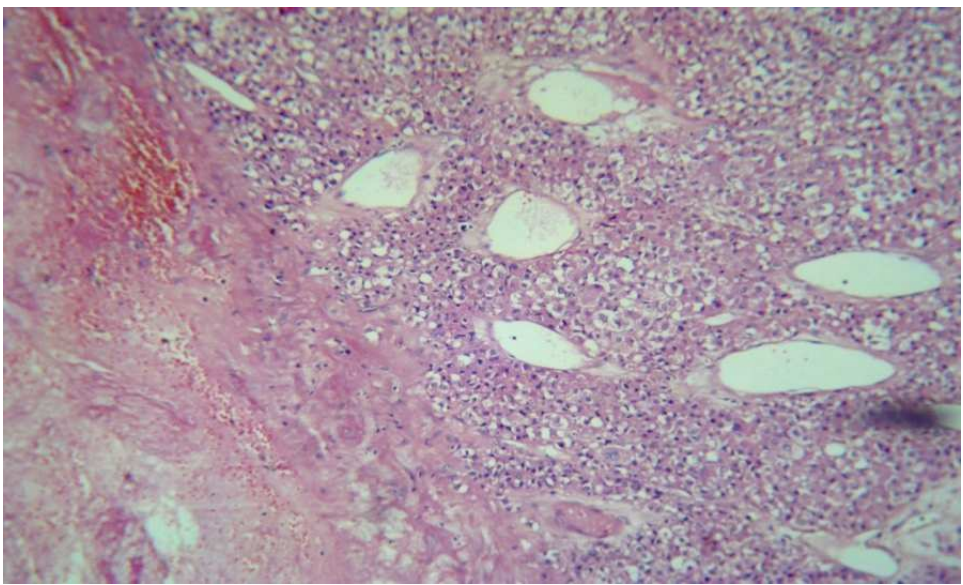

Slide showing tumour cells with clear cytoplasm and rich vascularity 


\section{CASE REPORT}

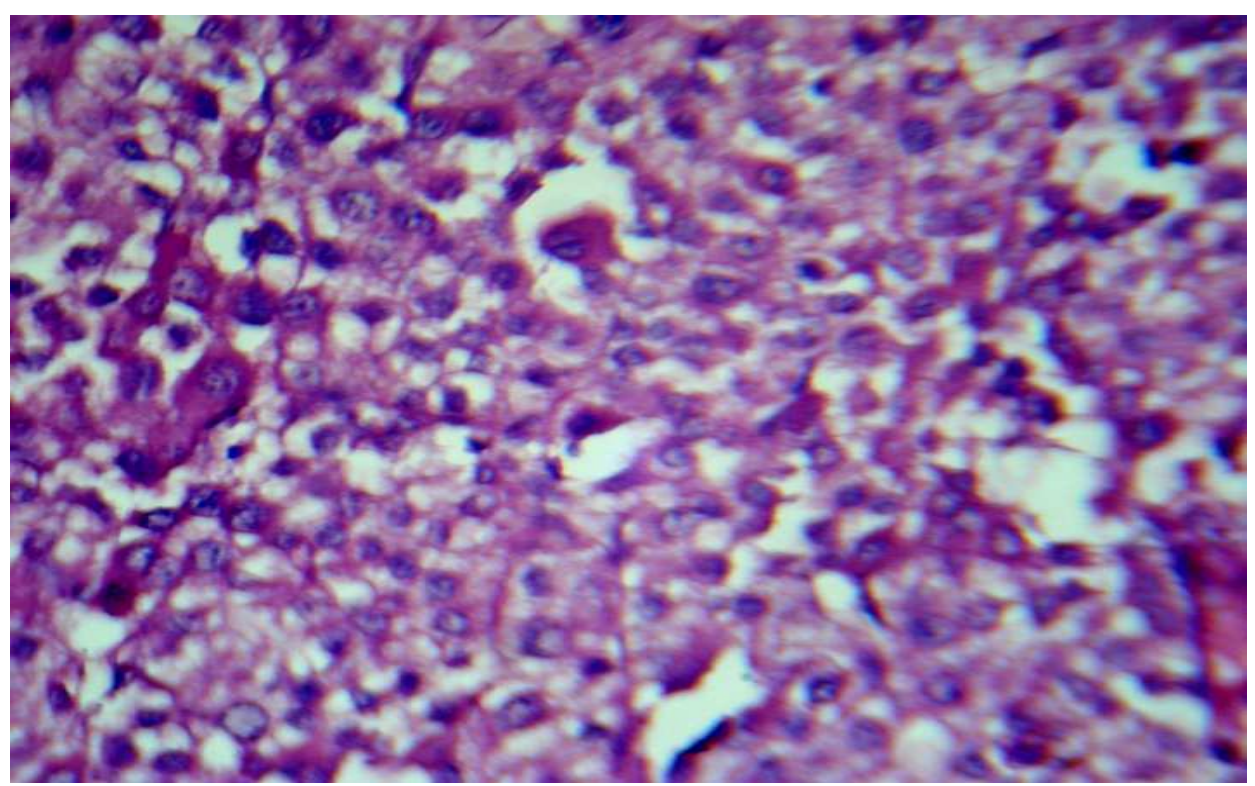

Slide showing active mitosis within the cell

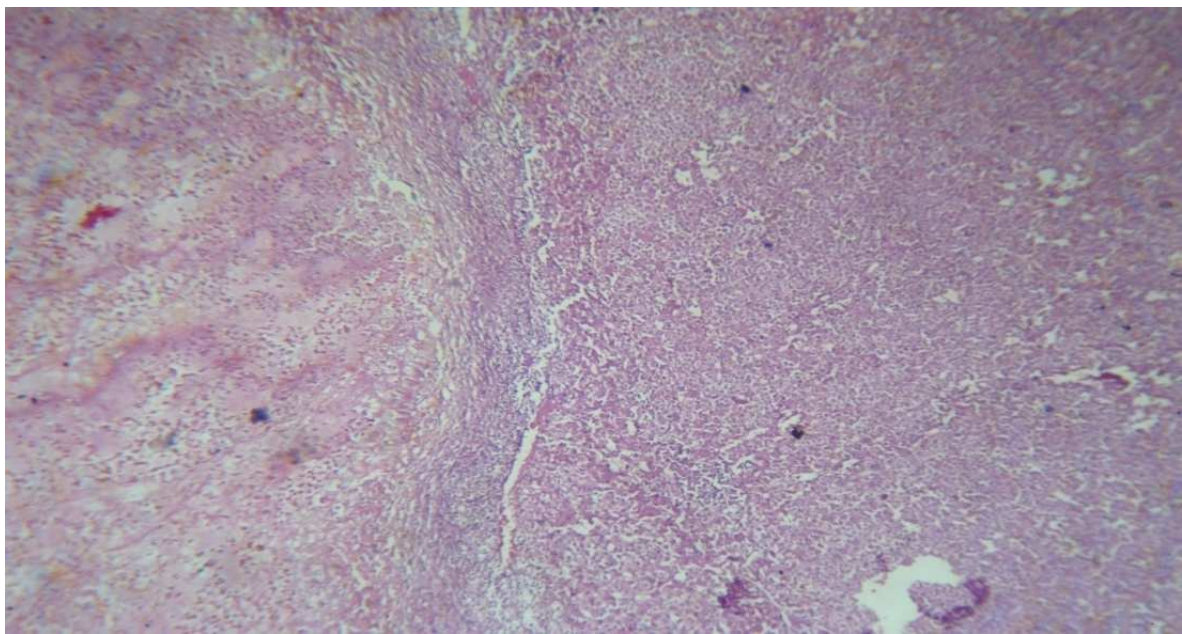

Slide showing areas of necrosis on the left hand side and viable area on the right hand side with tumour cells in sheets 